\title{
L-Band Polarimetric Target Decomposition of Mangroves of the Rufiji Delta, Tanzania
}

\author{
Ian Brown 1,2, ${ }^{\text {, Simon Mwansasu }}{ }^{1,3}$ and Lars-Ove Westerberg 1,2 \\ 1 Department of Physical Geography, Stockholm University, 10691 Stockholm, Sweden; LOW@natgeo.su.se \\ 2 Bolin Centre for Climate Change, Stockholm University, 10691 Stockholm, Sweden \\ 3 Institute of Resource Assessment, University of Dar es Salaam, PO Box 35097, Dar es Salaam, Tanzania; \\ SMwansasu@hotmail.com \\ * Correspondence: Ian.Brown@natgeo.su.se; Tel.: +46-8-163-984; Fax: +46-8-164-818
}

Academic Editors: Randolph H. Wynne, Parth Sarathi Roy and Prasad S. Thenkabail Received: 27 August 2015; Accepted: 1 February 2016; Published: 9 February 2016

\begin{abstract}
The mangroves of the Rufiji Delta are an important habitat and resource. The mangrove forest reserve is home to an indigenous population and has been under pressure from an influx of migrants from the landward side of the delta. Timely and effective forest management is needed to preserve the delta and mangrove forest. Here, we investigate the potential of polarimetric target decomposition for mangrove forest monitoring and analysis. Using three ALOS PALSAR images, we show that L-band polarimetry is capable of mapping mangrove dynamics and is sensitive to stand structure and the hydro-geomorphology of stands. Entropy-alpha-anisotropy and incoherent target decompositions provided valuable measures of scattering behavior related to forest structure. Little difference was found between Yamaguchi and Arii decompositions, despite the conceptual differences between these models. Using these models, we were able to differentiate the scattering behavior of the four main species found in the delta, though classification was impractical due to the lack of pure stands. Scattering differences related to season were attributed primarily to differences in ground moisture or inundation. This is the first time mangrove species have been identified by their scattering behavior in L-band polarimetric data. These results suggest higher resolution L-band quad-polarized imagery, such as from PALSAR-2, may be a powerful tool for mangrove species mapping.
\end{abstract}

Keywords: mangroves; synthetic aperture radar; polarimetry; ALOS PALSAR; deltas; Rufiji; L-band

\section{Introduction}

The mangrove forests of the Rufiji Delta are an important habitat and the largest estuarine mangrove area in East Africa. The mangroves are protected as a forest reserve subject to administrative and legal protections [1-3]. Nevertheless, the forest reserve is home to permanent and temporary/semi-permanent communities, which rely on the forest and marine environment for a range of resources and ecosystem services [3,4]. Mangrove forests are under increasing pressure from human exploitation. Additionally, natural threats, such as storms and changing sea levels, may adversely affect established mangrove forests. Changes in salinity and inundation patterns may impact the regeneration and species composition of forests $[5,6]$. The pressures on the mangroves of mainland Tanzania have led Mangora to conclude that their survival is in doubt [7]. Hence, tools are needed with which to survey mangrove forests, their composition and health.

Field surveys of mangrove forests are difficult to perform [5]. Access to forests beyond the immediate margins of waterways is made difficult by forest density and the structure of trees, particularly their roots. Access on foot is hampered by inundation and often by dangerous wildlife. 
Access by boat is hindered by dense vegetation, mudbanks and other physical obstacles. Field surveys therefore tend to use spatially-discrete sampling and lack wide areal coverage. Hence, mangrove forest mapping has traditionally utilized high resolution aerial photography [8,9]. Manual interpretation based on texture, reflectance and context is typically used to derive maps of dominant species. Optical remote sensing data have been widely used for mangrove mapping due to the availability of very high resolution imagery and the differences in spectral reflectance between mangrove species [8-10]. The availability of very high resolution satellite imagery and particularly multispectral imagery has led to the propagation of satellite remote sensing methods [8,9], but such systems are limited in utility by the prevalence of cloud at mangrove sites and by narrow spatial coverage. Synthetic aperture radar (SAR) data have been explored for mangrove forest mapping. SAR offers benefits that include negligible sensitivity to cloud or precipitation, wide spatial coverage and sensitivity to the physical structure of forests.

Backscatter coefficients from co- and cross-polarized data have been used to estimate mangrove forest biomass up to a cut-off at $100-140 \mathrm{Mg} \cdot \mathrm{ha}^{-1}$ [10]. This demonstrates the link between L-band SAR backscatter and bio-physical or allometric variables. However, L-band backscatter responses to biomass are non-linear; in dense forests, backscatter decreases with increasing aboveground biomass over $\sim 150 \mathrm{t} \cdot \mathrm{ha}^{-1}$ [10-12]. In temperate forests, [10] showed that decreases in backscatter occurred where tree biomass exceeded $7 \mathrm{~kg} \cdot \mathrm{m}^{-2}$ at the L-band and attributed the decrease to the attenuation of ground-trunk and surface scattering. The work in [12] showed using both experimental and theoretical approaches that decreases in HV backscatter are caused by signal attenuation in dense canopies. Decreases of $\sim 0.5 \mathrm{~dB}$ are expected for biomass increases between 150 and $550 \mathrm{t} \cdot \mathrm{ha}^{-1}$. This may lead to underestimations of biomass in measures based on L-band backscatter intensity. Furthermore, polarimetric measures that rely on HV data to estimate volume scattering may underestimate volume scattering over high density forests due to attenuation in the canopy. It should be noted that this study concerns mangrove forests with aboveground biomass well below $100 \mathrm{t} \cdot \mathrm{ha}^{-1}$.

Simple differences in L-band backscatter have been used as the basis for change detection [11,13]. Cornforth et al. [13] mapped changes in $\mathrm{HH}$ and HV backscatter $>10 \%$ in multi-temporal ALOS PALSAR imagery in an attempt to identify storm damage in Bangladeshi mangroves associated with Cyclone Sidr. The authors noted however that changes in soil moisture and tides were unaccounted for. Nor does simple change detection provide information on backscatter processes and the scattering responses of canopy, trunk and ground surface elements. The influence of stand structure and inundation on backscatter coefficients has been investigated using C-, L- and P-band datasets [11,14]. L-HH backscatter was modelled under flooded and non-flooded conditions, and clear backscatter amplitude differences were associated with the flood conditions [15]. Good agreement between the model and Shuttle Imaging Radar (SIR-B) SAR data led Wang and Imhoff [14] to conclude that differences between wet and dry surface conditions below mangrove canopies could be determined from L-band HH polarized SAR images. Analyses of forest structure provide potentially more valuable data to managers and ecologists. Using PALSAR data and Landsat, foliage protective cover (FPC) measures [16] were able to map the growth stages of regenerating tropical forest dominated or co-dominated by brigalow, a species of acacia. The Landsat FPC data improved classification accuracy by introducing woody biomass parameters that improved the classification of regrowth stage; with three classes of growth stage accuracies exceeding 70\%; with only two classes' accuracies reaching $90 \%$ [16]. For boreal forest sites, polarimetric models have been used to discriminate between deciduous and coniferous species [17] and to analyze the canopy and ground-trunk scattering components [18]. PolSAR methods have been developed to detect land cover types in a tropical forest region [17] and to study the growth of forest and agricultural vegetation $[19,20]$, but have not been applied to mangrove forests. Proisy and colleagues pioneered the investigation of polarimetric datasets for the analysis of mangrove forests [15]. They analyzed the polarimetric response of mangroves at C-, L- and P-band. They were able to identify growth stages using the ratio of co- and cross-polarization backscatter (the polarization ratio); L-band data were particularly effective. A simple backscatter model was used to 
identify the contributions of double-bounce, volume and surface scattering. Responses from pioneer stands were dominated by double-bounce scattering as a result of reflection at the ground or water surface. Open stands exhibited greater surface scattering at L-band, except in the HV channel, where volume scattering from the canopy and double-bounce scattering from the trunk-ground interface were the most significant components of backscatter. However, no decomposition of scattering was performed on image data to validate the model. Indeed, little attention has been given in the literature to polarimetric target decompositions for mangrove forest analyses despite a range of methods developed for the analysis of vegetation polarimetric responses. This is a significant knowledge gap given the increasing availability of polarimetric L-band SAR data and the continued development of target decompositions for vegetation-related analyses.

Here, we assess the potential of L-band PolSAR target decompositions for mangrove forest investigations. We processed and analyzed a multi-temporal dataset comprising three ALOS PALSAR polarimetric SAR (PolSAR) scenes over the northern and central Rufiji Delta, Tanzania. Backscatter was decomposed using eigenvector and backscatter model approaches. Entropy $(H)$, anisotropy $(A)$ and alpha angle $(\bar{\alpha})$ were calculated [21] and Yamaguchi and Arii target decompositions [22-24] applied. The results are compared to very high resolution imagery from ALOS PRISM and IKONOS and to existing maps. Limited field verification was performed. The information richness of the L-band PolSAR data is emphasized by the results.

\section{Study Area and Data}

The largest continuous mangrove forest in East Africa is found in the Rufiji Delta. The delta includes around $500 \mathrm{~km}^{2}$ of mangrove forest [25]. Eight main channels dissect the delta, which is East Africa's largest. The north delta, north of the Bumba River (Figure 1), has the largest mangrove area (ca. $46 \%$ of the total) and is more accessible and therefore more frequently utilized by local and commercial interests than the other parts.

All common mangrove species are found in the northern delta, where the main species are Rhizophora mucronata (red mangrove), Avicennia marina (grey mangrove), Ceriops tagal (spurred mangrove) and Sonneratia alba (white mangrove) [25]. Bruguiera gymnorrhiza (black mangrove) is also found in the northern delta. The central delta is the area between the mouths of the Bumba and $\mathrm{Ng}^{\prime}$ endu rivers. Here, the mangrove cover is $c a .29 \%$ of the total area. All mangrove species are well represented, but unlike all other mangrove forests in in Tanzania, Heritiera littoralis (looking glass mangrove) is a dominant species, occurring in almost pure stands reaching a height of $20 \mathrm{~m}$. Areas dominated by Heritiera littoralis are favored for rice cultivation and are more often clear-cut than other mangrove areas. In addition to the mangrove forest, coconut trees are found around settlements.

A mangrove forest reserve map was published by the Ministry of Lands, Natural Resources and Tourism in 1990, although we have not used the map for calibration or validation. The map is based on aerial photo interpretation and (presumably limited) field verification. However, the data were acquired in 1988/1989 and may not represent the current status of the forest. River course changes, resulting from flooding, are known to occur periodically [26] and are likely to affect mangrove species distribution as a result of geomorphic change and changes to fresh water routing; nor are there metadata detailing mapping resolution, validation or accuracy assessments. Given the uncertainties related to the currency of this map, we have avoided relying on it for mapping wherever possible. It was however necessary to use the map for species classification, as no other sources are available. Limited field work was performed in June 2014, to identify current species distributions at selected sites (identified in Figure 1). Tree heights were estimated by eye, and diameter at breast height (DBH) was measured for a small sample of trunks. However, as noted above, extensive mapping in situ was not possible. We have also inspected very high resolution optical imagery from ALOS PRISM to support PolSAR analyses. 


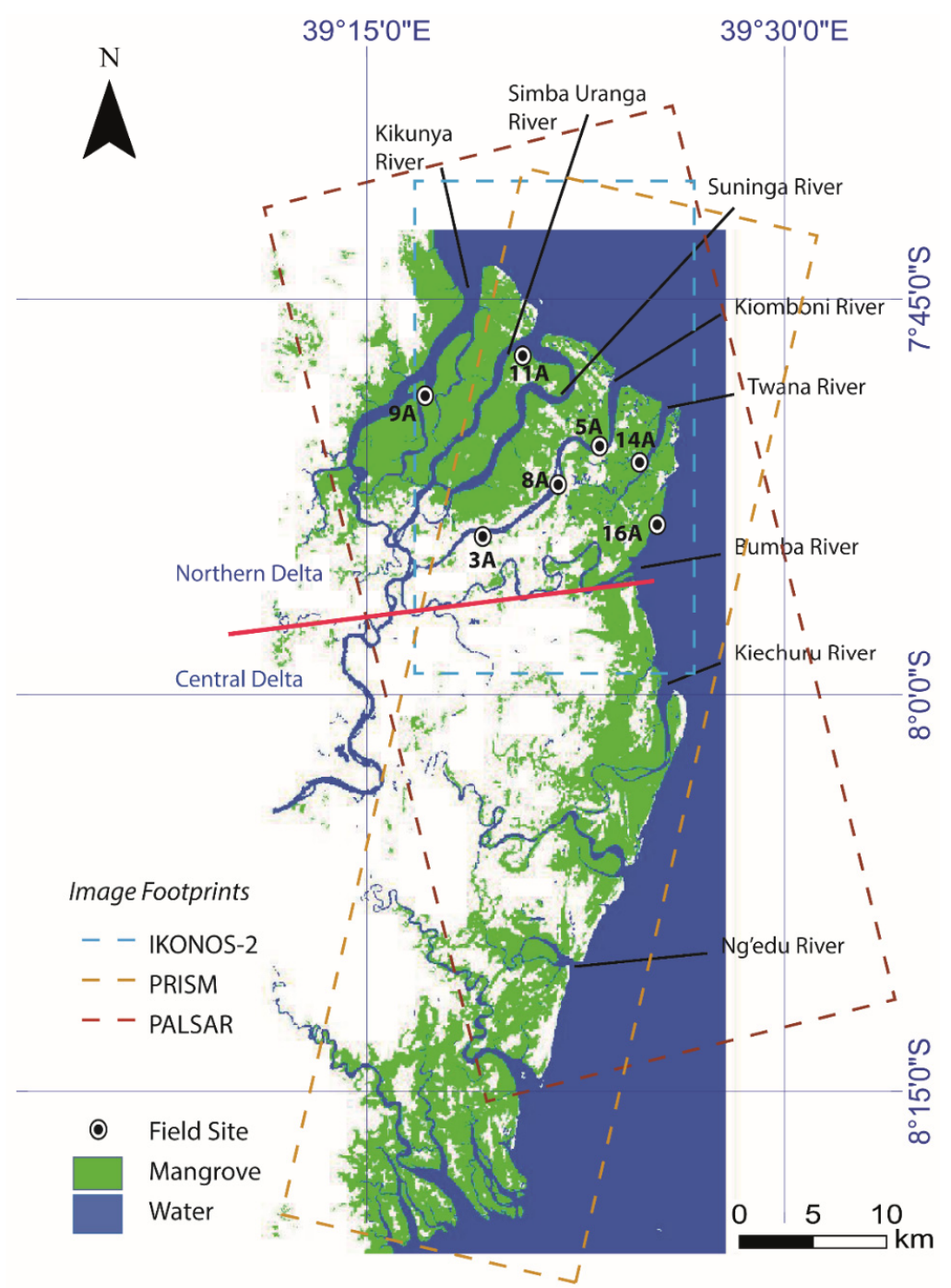

Figure 1. Map of the Rufiji Delta mangrove forests based on Landsat-5 TM data from 12 June 2008. The footprints of the satellite imagery and field sites are marked. The nominal division between the northern and central delta is indicated with a red line. The area of mangrove in the northern delta matches closely the mapping based on data from 2010 [3].

\subsection{Characteristics of Rufiji Mangrove Species}

The mangrove species found in the Rufiji Delta vary greatly in their physical characteristics, such as tree height and root structure, as well as in their ecology and distribution. Furthermore, different species are utilized in different ways by local and commercial interests, which can result in differential exploitation. Certain species, for example those used for firewood and local construction, may be thinned rather than clear-cut, whilst accessible stands of larger trees may be commercially felled, often illegally, in a clear-cut fashion [25]. Field observations revealed selective felling of Bruguiera gymnorrhiza and Sonneratia alba at neighboring sites near the mouth of the Simba Uranga River in the central northern delta. The former is known to be used in construction and the latter in carpentry.

The organization, ecology and distribution of African mangroves are described by [27] (Figure 2). On the seaward margin of the mangrove forest, Sonneratia alba is found. This may occur as shrubs or trees between 3 and $20 \mathrm{~m}$ in height surrounded by finger-like breathing roots protruding from the sediment up to a $0.75 \mathrm{~m}$ high. Rhizophora mucronata is also found on the seaward side and around the mouths of rivers. Trees may be up to $25 \mathrm{~m}$ tall and are characterized by extensive stilt roots. On the landward side and on raised banks, Heritiera littoralis may be found. These trees may reach heights of 
$21 \mathrm{~m}$ supported by thin buttresses. Ceriops tagal is also associated with shoreward locations and thin strips along sandy creek banks. These are trees or shrubs not normally more than $6 \mathrm{~m}$ tall. The trees grow small buttress roots radiating from the lower stem and forming knee-like roots emerging from the soil. On inland fringes and mudbanks, Avicennia marina is found; Avicenna is a pioneer species and may even be found on seaward fringes of the forest. Growing as a shrub or tree 1-15 $\mathrm{m}$ tall, this species may be surrounded by dense networks of linear breathing roots extending up to $0.6 \mathrm{~m}$ from the soil. Lumnitzera racemosa and Xylocarpus granatum are found at the landward side of the mangrove forest; the former grows up to $9 \mathrm{~m}$ tall; the latter grows up to $15 \mathrm{~m}$ and prefers tidal flats. Bruguiera gymnorrhiza may be found throughout the mangrove forest, where fresh water is prevalent. The tree may grow up to $30 \mathrm{~m}$ tall, has a thick crown and is supported by short buttresses.

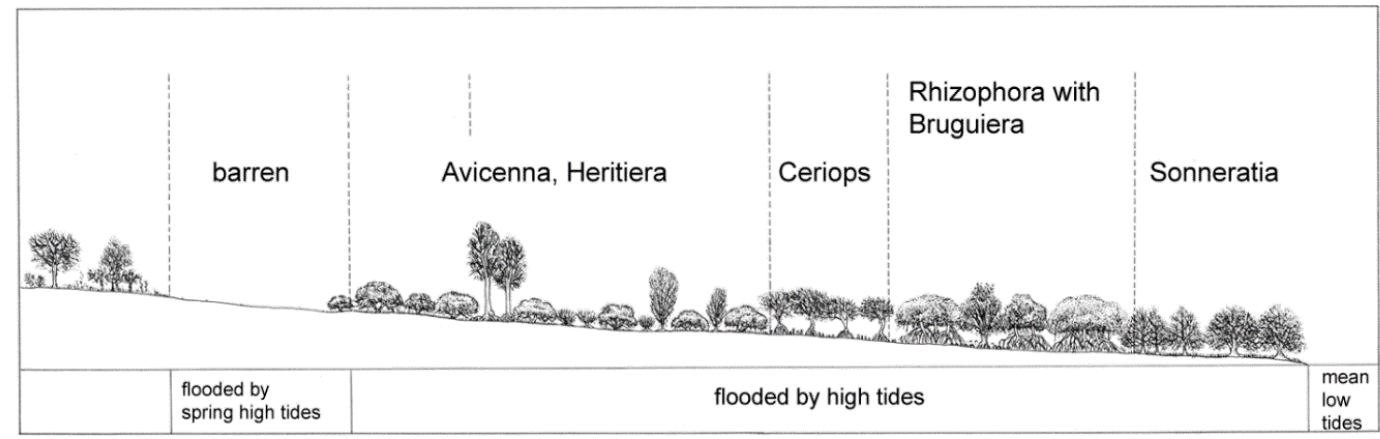

Figure 2. The zonation common to East African mangrove forests [27].

\subsection{Satellite Imagery}

Three ALOS PALSAR L-band quad-pol image datasets were used in the analysis. The image slant range resolution was $23 \mathrm{~m}$ in range and $3.5 \mathrm{~m}$ in azimuth. The images were acquired on 24 May 2007, 13 April 2009 and 2 December 2010. Hereafter, we refer to the images by the year of their acquisition. In the absence of tide gauge data, estimated tidal height and mean monthly historical discharge were used to estimate the relative water level at the study site at the given acquisition times. The 2007 image was acquired less than an hour after high tide in Dar es Salaam, approximately $115 \mathrm{~km}$ north of the delta; tide height in Dar es Salaam was over $2.0 \mathrm{~m}$ at the time of image acquisition. The 2009 image was acquired within an hour of low tide with a tide height of $<0.5 \mathrm{~m}$. The 2010 image was acquired less than two hours before a high tide with a tide height around $2.0 \mathrm{~m}$ in Dar es Salaam. Tide heights were estimated using the XTide calculator [28]. Mean monthly river discharge measured upstream at Stieglers Gorge suggests peak discharge occurs during March-April with a peak of over $2000 \mathrm{~m}^{3} \cdot \mathrm{s}^{-1}$ falling to less than $1000 \mathrm{~m}^{3} \cdot \mathrm{s}^{-1}$ in late May and with an annual low around $250 \mathrm{~m}^{3} \cdot \mathrm{s}^{-1}$ in October. Early December mean discharge was just below $500 \mathrm{~m}^{3} \cdot \mathrm{s}^{-1}$ [29]. Hence, the 2007 image was acquired during high water, the 2009 during low water and 2010 images during moderate water levels. Coastal flats are evident in the 2009 data, indeed suggesting low tidal heights; similar features are found in the majors rivers. The emergence and extent of islands in the rivers of the delta suggest a higher water level in the December 2010 image than in the May 2007 image. It should be noted that flow rates of the Rufiji River and its tributaries are regulated by dams upstream.

In addition to the PALSAR imagery, ALOS PRISM high resolution panchromatic images were acquired over the site. Four images covering the eastern parts of the northern and central delta were acquired; two from 21 October 2007 and two from 23 October 2008. The PRISM images were acquired during the period of lowest discharge in the Rufiji River and during approximate tidal heights of $2 \mathrm{~m}$ in Dar es Salaam. The data used were nadir looking with a spatial resolution of $2.5 \mathrm{~m}$. Two IKONOS multispectral scenes were acquired over the northern delta on 10 December 2008; the spatial resolution of these data are $<4 \mathrm{~m}$, whilst the associated panchromatic imagery was acquired at a $<0.6-\mathrm{m}$ spatial resolution. All scenes contain cloud cover, obscuring parts of the images (around 20\%). 


\section{Methods}

The SAR images were acquired under the European Space Agency-Japanese Aerospace Exploration Agency ALOS European Data Node (ADEN) program. The images were received as Level 1.1 complex quad-pol data. The data were delivered corrected for the elevation antenna pattern, range spreading loss and with projected pixel area normalization applied [30]. An Ainsworth calibration was applied to correct for cross-talk [31]. The data were then multi-looked to $25 \mathrm{~m}$ (1 and 5 looks in range and azimuth, respectively) and speckle filtered using a refined Lee filter with a window size of $7 \times 7$ [24,32]. The data were geocoded and reprojected to geographic coordinates with a WGS84 datum using an SRTM DEM. Geocoding was performed using the range-Doppler equations, and radiometric correction was applied according to [33]. It should be noted that the study area lacks steep topography and, as is the case with most deltas, is largely flat. The processing resulted in imagery with a grid spacing of $25 \mathrm{~m}$ and an equivalent number of looks of 157-163 [24]. The standard deviation of backscatter intensity (HH-polarized data from 2010) was $-13 \mathrm{~dB}$. The ground resolution after applying decompositions was estimated to be $50 \mathrm{~m}$ for the model-based target decompositions and $200 \mathrm{~m}$ for the entropy-anisotropy-alpha decompositions. These estimates are based on the ability to resolve smaller creeks. Following, the pre-processing target decompositions were applied.

Using an eigenvector analysis of the coherency matrix [21,34,35] showed that roll-invariant parameters can be used to describe scattering. Scattering entropy $(H)$, anisotropy $(A)$ and the mean alpha angle $(\bar{\alpha})$ are derived from second order statistics that do not rely on an assumed statistical distribution. However, the results are not physically related to scattering processes, and interpretation is required. Nevertheless, the $H / \mathrm{A} / \bar{\alpha}$ decomposition is something of a classical polarimetric method, and hence, we have included the results of the $H / \mathrm{A} / \bar{\alpha}$ decomposition in this study. The projection of scattering power to $H / \bar{\alpha}$ and $H / \mathrm{A} / \bar{\alpha}$ space is used to classify scattering. Low entropy $(H<0.3)$ indicates a weakly-depolarizing point scatterer. Anisotropy, $A$, is generally employed when high values of entropy are found $(H>0.7)$. Anisotropy is the normalized difference of the second and third eigenvectors; these are subject to greater noise, and hence, $A$ is considered only when noise effects are reduced, as in the case of higher entropy. High anisotropy in the presence of high entropy suggests two scattering mechanisms [21,24], whilst low anisotropy would suggest random scattering in the presence of high entropy. High entropy has been associated with secondary and tertiary scattering in tropical forests [36]. Low anisotropy was characteristic of forests and mangroves, whilst higher values were found over grasslands and cleared sites. Thus, the $A$ parameter enables us to better distinguish mechanisms occurring under high entropy. The alpha parameter, $\bar{\alpha}$, describes the range of scattering mechanisms: surface scattering from a smooth surface through rough surface scattering, single scattering from a cloud of anisotropic particles and double-bounce scattering to dihedral scatter from a metallic surface [24]. Typically, nine classes are derived from the former, which themselves can be grouped into double-bounce, volume and surface scattering. Alternatives to the Cloude-Pottier entropy-alpha have been proposed: [37] demonstrated a computationally-efficient alternative that generated scattering diversity and surface scattering fraction measures. It was argued that these measures offer advantages in the ease of interpretation over the more ambiguous $H / A$ terms. However, given the classical nature of the Cloude-Pottier approach, we have chosen to implement the original model, rather than that of [37]. We leave an analysis of alternatives to the Cloude-Pottier method [21] to future work.

An alternative to the eigenvector/eigenvalue analysis is model-based target decompositions. Incoherent target decompositions (ITD) are appropriate for distributed targets and cases where coherence between elements is not assumed. Model-based ITDs have been developed to decompose the backscattered power into its constituent elements $[18,19,22,23]$. The simplest ITD is a two-component model describing surface and volume scattering [18]. More typically, three or more components are considered: a non-penetrable surface, a dihedral component that promotes multiple scattering (also known as double-bounce) and a volume of particles. Four-component models may include helical scattering from highly complex or man-made targets. The Freeman-Durden decomposition [19] is 
a three-component decomposition. In this approach, volume scattering is estimated using the HV channel. The Freeman-Durden model then assumes a dominant scattering mechanism, reducing the number of parameters to be solved, allowing the model to decompose total backscattered power into dihedral, surface and volume components. The four-component Yamaguchi model [22] extends the Freeman-Durden model by adding a helical component. The model is roll-invariant and does not assume reflection symmetry. The application of a unitary transformation further improves the model using the full information available from the coherency matrix. This modified 4-component model offers four volume scattering cases, which are differentiated by the probability distribution function (PDF). The model structure therefore seeks to optimize the selection of the vegetation model and furthermore defaults to a three-component model in the absence of helical scatterers. We chose to apply the modified Yamaguchi decomposition, also known as the General 4-component model with Unitary transformation (G4U) model, as an example of a Freeman-Durden-type approach. There are known limitations of these types of models. Such models may overestimate volume scattering from vegetation, as evidenced by negative eigenvectors representing the non-volume scattering remaining of the covariance matrix $[23,38]$. Such limitations have led to the development of a three-component model using thin cylinders and a generalized PDF to model scattering from the canopy [23]. The PDF does not allow for negative eigenvalues and therefore avoids misrepresenting volume scattering in the manner identified in [23]. It has also been noted that characterizing the vegetation canopy as a collection of thin dipoles represented by a PDF may be a limitation [23,39]. Step-wise dependencies of the canopy model on the PolSAR data have also been challenged, and alternatives have been proposed [39].

This "Arii" model was applied here for comparison and evaluation against the Yamaguchi G4U model. These models are derivations of the popular Freeman-Durden model and are widely available through the European Space Agency's PolSARPro software package.

\section{Results and Discussion}

\subsection{Entropy-Anisotropy-Alpha}

Roll-invariant scattering entropy $(H)$, anisotropy $(A)$ and alpha angle $(\bar{\alpha})$ were calculated (Figure 3$)$, and the data distributions in the $H / \bar{\alpha}$ plane were projected (Figure S3 in the Supplementary Materials). $H / A$ combinations were also generated (Figure 3). Alpha angles were highest over sites cleared for settlements and agriculture and coastal Sonneratia stands around Site 16A (Figure S1 in the Supplementary Materials). This may reflect double-bounce effects from water-trunk angles. The lowest $\bar{\alpha}$ response was from Site $8 \mathrm{~A}$, a settled island with rice and coconut cultivation, in 2010 . The lower $\bar{\alpha}$ response may indicate surface scattering from flooded rice paddies. Preparation of fields begins in December; the IKONOS images from December 2008 appear to show flooded rice paddies.

Entropy was found to be high over most targets in each of the three years (Figure 4); the exceptions being rivers and grasslands, the latter particularly in the December 2010 data. $H / \bar{\alpha}$ data acquired over hardwood forests in Queensland, Australia, exhibited very high values of $H$ over mature forest stands, leading to difficulties in differentiating scattering mechanisms [38]. In all years, Sonneratia sites (11A, 16A; Figure S4 and Figure S5 in the Supplementary Materials) demonstrate mean values (0.74-0.78) slightly lower than Rhizophora- and Avicennia-dominant sites (14A, 9A and 5A), which exhibit $H$ values of $0.81-0.84$ (Table S1 in the Supplementary Materials). Inundated regions in the Amazon have been found to result in very high $H / \bar{\alpha}$ values ( $>0.8$ and $50^{\circ}$, respectively) [40]. However, our results show that the sites that are typically inundated (16A and 11A) do not exhibit high entropy and are characterized by lower alpha angles. The Sonneratia at the study sites were relatively large specimens; significantly larger than the Rhizophora trees around Site 14A. Whilst structural influences may contribute to differences in $H / \bar{\alpha}$ [40], the lower entropy of the (inundated) rice fields at Site 8A might indicate a hydrological control on the lower entropy at the flooded sites. The work in [40] reports lower entropy over riparian forest sites than over primary forest or advanced secondary forest 
with similar tree heights. Their results showed a marked reduction in both entropy and alpha angle between wet and dry seasons. Hence, we attribute the lower entropy at our inundated sites with higher double-bounce scattering and lower depolarization. We note that the Sonneratia and coconut trees are characterized by relatively straight trunks without buttress or stilt roots; complex buttress roots or dense stilt roots may promote high entropy from multiple scattering, whilst causing depolarization.

The $H / A$ results imply anisotropic and/or rough surface scattering over forests and mangroves, typically from a single dominant scattering mechanism (Figure 3). Low entropy over grasslands between the Bumba and Kiechuru rivers suggests surface scattering. High alpha angle values were found over cleared sites, particularly on the Kiomboni River (Sites 3A and 8A) in 2007 and 2009, which according to the $H / \bar{\alpha}$ plane indicates double-bounce scattering. Care must therefore be taken when ascribing scattering mechanisms when $H$ approaches unity. Entropy values were lower in 2010, especially over the grasslands, where Bragg surface scattering is indicated, perhaps signifying inundation. On the $\mathrm{H} / \bar{\alpha}$ plane (Figure S3 in the Supplementary Materials) cleared and settled sites are projected on the boundary of the anisotropic particles/double-reflection propagation effect zones. Moderately high anisotropy may indicate that there are multiple scattering mechanisms. Coconut trees and even remnant mangrove stands are prevalent in cleared areas, and thus, multiple mechanisms can be conjectured: as double-bounce scattering from trunk and the ground or wetted ground surface, or from the wetted ground and field boundaries; volume scattering from canopy elements and mature rice plants; and surface scattering from open areas without tall plant cover (e.g., rice fields prior to inundation). Selective felling practices result in a complex pattern of land cover that can cause difficulties in classifying scattering [40].
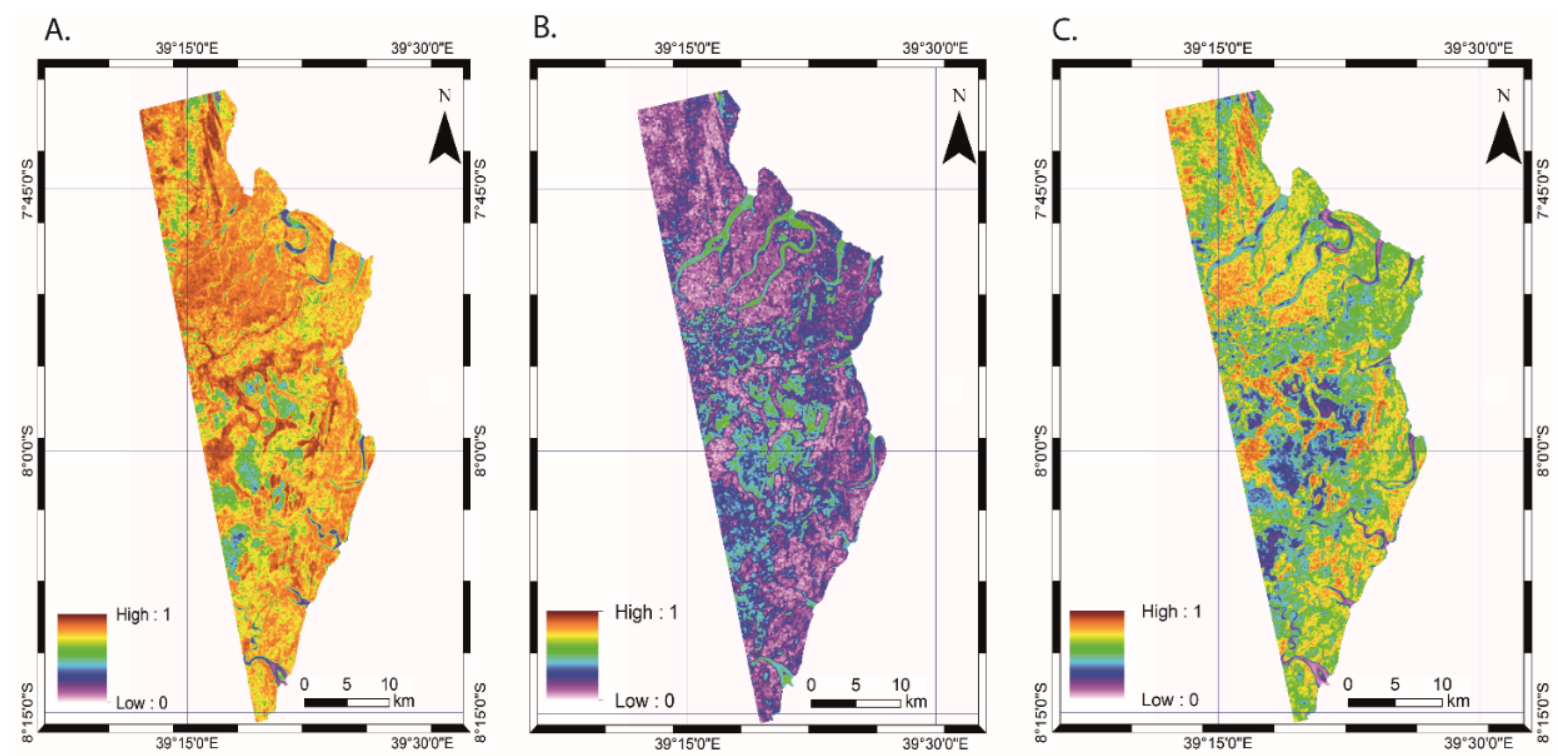

Figure 3. Entropy (A), anisotropy (B), and alpha angle (C) calculated from the 2009 PALSAR dataset over the Rufiji Delta, Tanzania. The alpha angle units are radians. Anisotropy is a measure of the relative importance of the second and third eigenvectors and as such is complementary to entropy. Low entropy values lead to high noise in the eigenvectors used to derive anisotropy. Hence, anisotropy is only used in the presence of high entropy.

Plants may reach maturity in early summer, meaning the 2007 data, and possibly the 2009 data, are likely to have been acquired under such conditions. Anisotropy over the rice fields at Sites 3A and 8A was distinctly lower in the 2010 data than in the other two years, implying a single dominant mechanism. 


\subsection{Incoherent Target Decompositions}

The two model-based target decompositions were calculated to describe the scattering contributions from the trunk-ground interface (double-bounce), canopy (volume scattering) and ground or water surface (surface scattering). The aim with this analysis was the determination of scattering differences between species and over time.

The Yamaguchi and Arii decompositions are dominated by volume scattering over mangrove forests with double-bounce scattering only significant where inundation occurs (Figure 4 and Figure S4). Low canopy closure is associated with surface scattering. Helical scattering is absent from the scenes, even from villages, reflecting the absence of infrastructure [41]. The Yamaguchi model reverts to a three-component description of scattering in the absence of helical scatterers. The main mangrove forests of the Kikunya and Simba Uranga rivers display dominant volume scattering (e.g., Site 9A; see Figure 1). Cleared areas along the Kiomboni River have higher double-bounce scattering than the mangrove forests (Sites 3A and 8A). Grasslands are typified by high surface scattering [41], and the lower biomass mangrove of the north-eastern delta around the Twana River exhibits relatively high volume and surface scattering, particularly in the 2010 data (Table S1 in the Supplementary Materials).
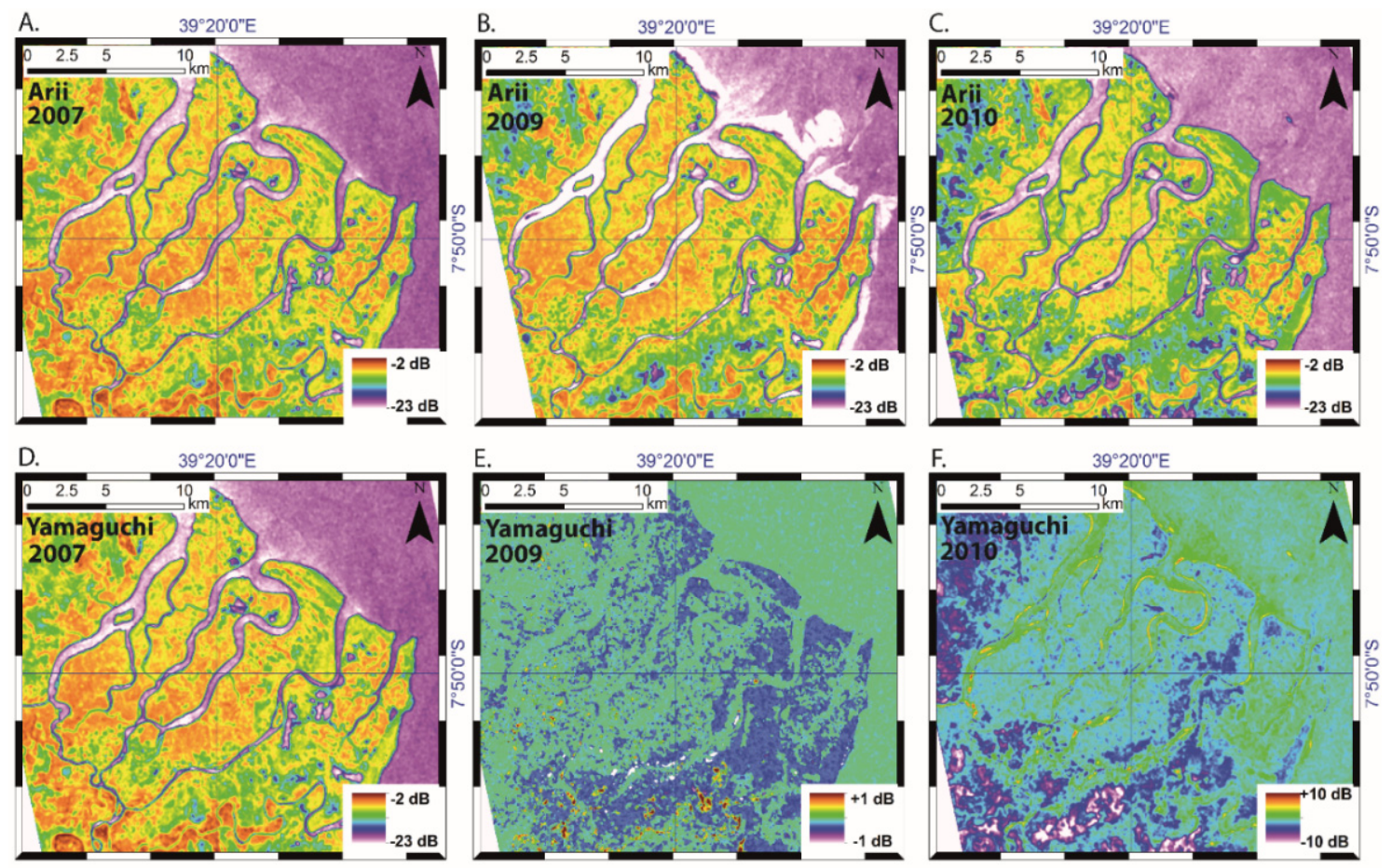

Figure 4. Volume scattering from the Arii and Yamaguchi models. (A) Arii volume scattering from the 2007 dataset; (B) Arii volume scattering from 2009; (C) Arii volume scattering from 2010; (D) Yamaguchi volume scattering from 2007 shows almost identical patterns to the Arii volume scattering; (E) The difference between the Arii and Yamaguchi models from 2007; (F) The difference between Arii volume scattering models from 2007 and 2010. Most of the strong negative differences are found over non-mangrove and non-agricultural locations.

The Arii model results were almost exactly the same as the Yamaguchi model (Figure 4). Differences in the volume scattering components between the models was never greater than $0.5 \mathrm{~dB}$. Double-bounce scattering was up to $4.8 \mathrm{~dB}$ lower in the Arii around the Simba Uranga River. However, it should be noted that this difference, between $-20 \mathrm{~dB}$ and $-15.2 \mathrm{~dB}$, was close to the noise floor of the data. Double-bounce scattering was generally higher in the Yamaguchi model than the Arii model. Surface scattering was often higher in the Arii model (typically by $<1 \mathrm{~dB}$ ), possibly indicating differences in the implementation of the double-bounce and surface scattering model terms and the 
role of a remainder term in the Arii model. The Yamaguchi model lacks a remainder term and reverts to three components in the absence of helical scattering. The high degree of similarity between the Yamaguchi and Arii model results suggests that over low biomass mangrove forests, the differences in the PDFs used in the volume scattering models have negligible effects.

\subsection{Differences in Scattering Mechanism between Mangrove Species}

No previous work has addressed mangrove species scattering mechanisms using target decompositions. Differences in canopy structure have been associated with different backscatter responses from mangrove stands of similar biomass using polarimetric ratios [14]. Polarimetric target decompositions make assumptions regarding the canopy structure in order to model volume scattering from vegetation $[18,19,22,23,41]$. Hence, it is understood that canopy structure is a major factor in volume scattering estimates. Phase center mapping in L-band interferometry has suggested that for HV polarized data, the phase scattering center is around $50 \%$ of the tree height [42]. Hence, scattering from the major branches and trunk might be expected to dominate scattering, and so, differences in tree structure will result in differences in scattering behavior.

Differences in the polarimetric responses of mangrove are evident in the target decompositions presented here (Figure 5). Species were identified using a combination of in situ observations cross-referenced with the 1990 Mangrove map. Sonneratia-, Rhizophora- and Avicennia-dominant stands were identified in situ; Ceriops was mapped using the map only and must therefore be treated with caution. IKONOS and PRISM data were used to ensure homogenous mapping units were found. Each mapping unit was >100 pixels; 501 pixels were sampled per mangrove species. In the 2010 data, Sonneratia returned the highest double-bounce response of the species (mean $-6.0 \mathrm{~dB}$ ); Avicennia and Rhizophora displayed mean double-bounce values of -16.6 and $-16.1 \mathrm{~dB}$, respectively. Similarly, Sonneratia returned the lowest entropy (0.76) and Avicennia next lowest (0.80). All species exhibited strong volume scattering responses: Rhizophora -5.8 ; Sonneratia $-6.8 \mathrm{~dB}$; Ceriops $-7.4 \mathrm{~dB}$; and Avicennia $-9.9 \mathrm{~dB}$.

Surface scattering responses were very low for Sonneratia (mean $=-18.1 \mathrm{~dB}$ ) and highest for Rhizophora $(-7.2 \mathrm{~dB})$. Surface scattering in forest stands is assumed to reduce with stand density and biomass [40]. The Rhizophora stands in the northeast of the delta are characterized by low crown coverage relative to the other mangrove species. A well-developed network of creeks is evident in the high resolution imagery over the area. Sonneratia, which exhibits dense stands with high canopy closure, was characterized by high double-bounce and low surface scattering. The Sonneratia response matches that of Amazonian riparian forest stands [41]. Modelling of backscatter responses from pioneer stands in South America has suggested double-bounce should dominate due to the high reflective surface at the base of trees [15]. Avicennia stands exhibit low double-bounce and volume scattering. Field surveys suggest Avicennia specimens typically have a DBH of $10-20 \mathrm{~cm}$ and are shorter than Sonneratia. Avicennia and Rhizophora develop broad dense canopies, unlike Sonneratia. Rhizophora and Ceriops both expressed high volume scattering and low double-bounce and surface scattering, though the mean Rhizophora volume scattering response was somewhat higher than that of Ceriops. This difference is almost certainly due to a combination of two factors; firstly, the greater biomass of the Rhizophora, the Ceriops often being $<6 \mathrm{~m}$ tall with a DBH of $<10 \mathrm{~cm}$, and secondly, the presence of well-developed stilt roots in Rhizophora stands, which contribute to sub-canopy volume scattering. Sonneratia's preference for seaward and flooded locations likely promotes double-bounce at the trunk-water interface. Sonneratia may also develop broad trunks at the base of the tree (e.g., [27]). The Sonneratia surveyed in the field tended to be large trees with DBH of $>20 \mathrm{~cm}$. Thus, forest structural characteristics can be employed to explain the differences in scattering between species. However, it must be restated that the widespread mixing of species across the delta makes classification impractical. Higher resolution data will be needed to support species classification using scattering decompositions. 


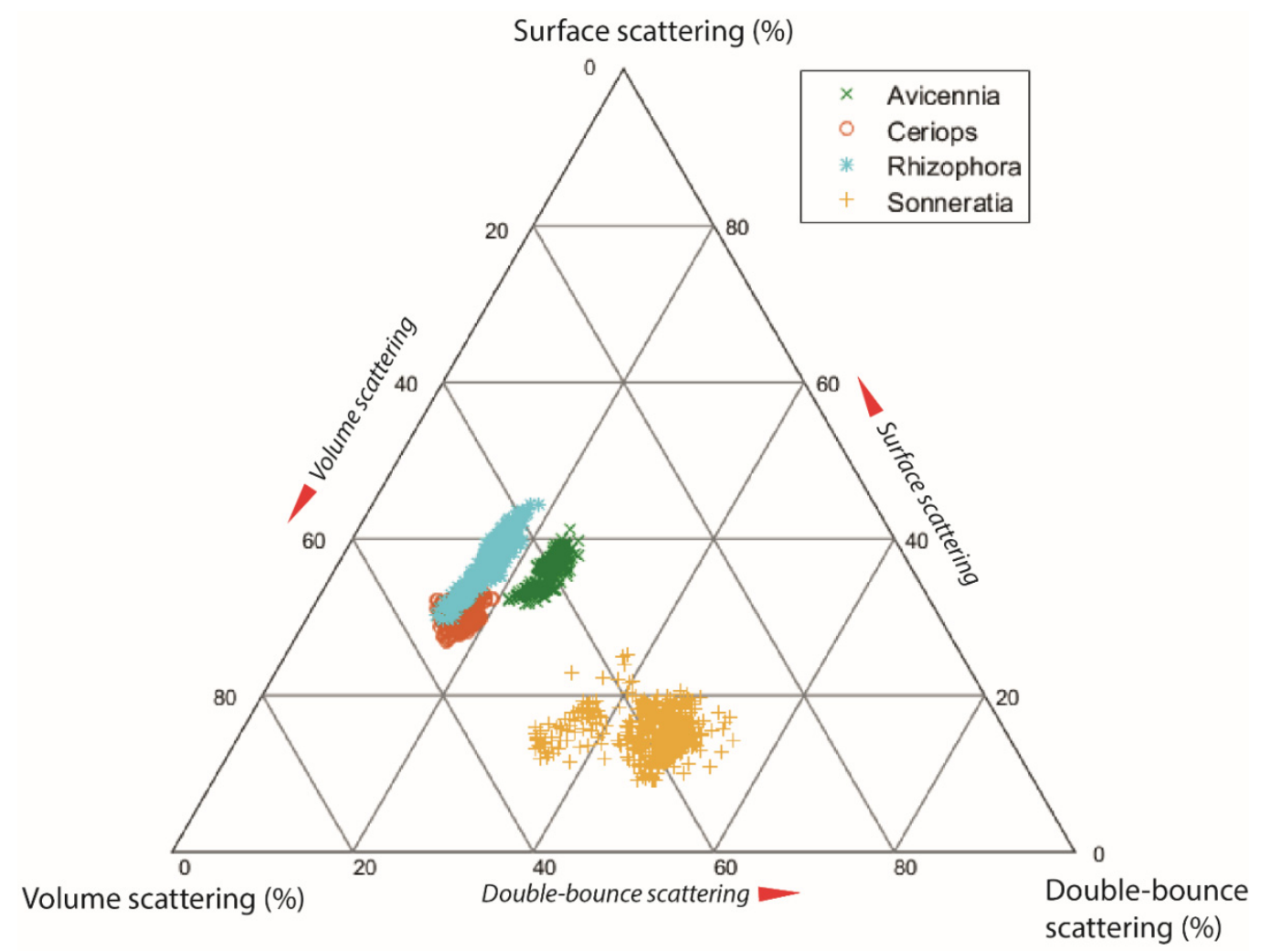

Figure 5. Relative contributions of Arii model decomposition terms by species using data from 2010. Some overlap between Rhizophora and Ceriops is evident and may represent impure stands, misclassification or the relatively high degree of spatial averaging in the data. Two populations of Sonneratia may be identified due to the degree of inundation promoting double-bounce scattering.

\subsection{Temporal Variations}

The principle temporal variations in the decompositions are related to the hydrology of the delta and some human activities. Double-bounce and volume scattering are higher at the southwestern landward periphery of the northern delta in 2007 than in 2009 and 2010 (Figure 4 and Figure S1 and Figure S4 in the Supplementary Materials). We associate this with the development of land for agriculture. The 2010 data display large areas of low surface scattering over grasslands and saltpans. Most mangrove stands exhibit relatively stable polarimetric responses between the three image datasets. Local differences were: double-bounce components varied more greatly than volume or surface scattering components as a result of differences in the dielectric properties of the ground surface as a function of wetness. Differences in the extent of cleared areas around settlements are also present. Large differences in response from non-mangrove regions between 2010 and the other two datasets are most likely due to changes in environmental conditions: the growing season, rainfall and flooding (e.g., [23,38]). The 2010 data exhibit a less dramatic difference between settled regions and the surrounding mangrove. We do not believe the mangrove forest has re-established within one year. Hence, we can expect seasonal differences in the response of land cover/land use classes due to climate and tidal forcings and agricultural practices. The smaller scattering differences in the mangrove forests suggests that multi-temporal imaging can identify mangrove as stable targets relative to grasslands and settlements. Similar results have been reported from tropical forests in India using $H / A / \bar{\alpha}$ decompositions [20]. 


\section{Conclusions}

This is the first known study to investigate the spatio-temporal patterns of backscatter mechanisms in mangrove forests using target decompositions. The Yamaguchi and Arii model-based target decompositions are shown to differentiate between species, although mixed-species stands likely preclude automated classification. Some differences between mangrove species of the Rufiji Delta are also evident in entropy-anisotropy-alpha. The high level of agreement between the Yamaguchi and Arii decompositions over the mangrove forest suggests that the choice of PDF has limited influence over dense vegetation, where filtering and ensemble averaging have been applied. The $H / A / \bar{\alpha}$ and ITDs showed differences in target response that can be equated to plant structural characteristics. This demonstrates that high resolution L-band PolSAR data, such as from PALSAR-2, could be used to classify species if sufficient validation data were available. There exist clear temporal differences in the polarimetric response of grasslands, settlements and agricultural land. Mangrove polarimetric responses were more stable over time, though local differences occurred, particularly at the seaward edge of the delta and where human activity is suspected. These methods, unlike those based on optical imagery, are independent of cloud cover and, thus, are more suitable for regular monitoring in support of activities, such as environmental management and storm damage assessment. Future work should address the phenological signature of mangrove species in polarimetric data to improve our understanding of mangrove phenology on L-band scattering.

Supplementary Materials: The following are available online at http://www.mdpi.com/2072-4292/8/2/140/s1, Figures S1-S7; Table S1.

Acknowledgments: The authors gratefully acknowledge financial support from the Swedish International Development Agency. ALOS data were provided by the European Space Agency and Japanese Aerospace Exploration Agency. IKONOS images were kindly provided by the GeoEye Foundation. The authors would also like to acknowledge ESA and the PolSARPro development team, as well as the Radar Tools (RAT) developers, in particular Andreas Reigber. Figure 5 was produced with code from Carl Sandrock and Norris Lam. Figure 2 is reproduced with the permission of the copyright holder (Juliet Williamson).

Author Contributions: Ian Brown processed the data and analyzed the results in discussion with Simon Mwansasu. Simon Mwansasu conducted the fieldwork. All authors contributed to the study design and writing.

Conflicts of Interest: The authors declare no conflict of interest.

\section{References}

1. Bryceson, I.; Massinga, A. Coastal resources and management systems influenced by conflict and migration: Mecufi, Mozambique. Ambio 2002, 31, 512-517. [CrossRef] [PubMed]

2. Masalu, D.C.P. Challenges of coastal area management in coast developing countries- lessons from the proposed Rufiji delta prawn farming project, Tanzania. Ocean Coast. Manag. 2003, 46, 175-188. [CrossRef]

3. Burgess, N.D.; Mwakalila, S.; Munishi, P.; Pfeifer, M.; Willcock, S.; Shirima, D.; Hamidu, S.; Bulenga, G.B.; Rubens, J.; Machano, H.; et al. REDD herrings or REDD menace: Response to Beymer-Farris and Basset. Glob. Environ. Chang. 2013, 23, 1349-1354. [CrossRef]

4. Semesi, A. Management Plan for the Mangrove Ecosystem of Mainland Tanzania; Ministry of Tourism, Natural Resources and Environment, Forestry and Beekeeping Division: Dar es Salaam, Tanzania, 1991; Volume 1-10.

5. Erftemeijer, P.; Hamerlynck, O. Die-back of the mangrove Heritiera littoralis dryland, in the Rufiji Delta (Tanzania) following El Niño floods. J. Coast. Res. 2005, 42, 228-235.

6. Hoppe-Speer, S.C.L.; Adams, J.B.; Rajkaran, A.; Bailey, D. The response of the red mangrove Rhizophora mucronata Lam. to salinity and inundation in South Africa. Aquat. Bot. 2011, 95, 71-76. [CrossRef]

7. Mangora, M. Poverty and institutional management standoff: A restoration and conservation dilemma for mangrove forests of Tanzania. In Proceedings of the 18th Commonwealth Forestry Conference, Edinburgh, UK, 28 June-2 July 2010.

8. Heumann, B.W. Satellite remote sensing of mangrove forests: Recent advances and future opportunities. Prog. Phys. Geogr. 2011, 35, 87-108. [CrossRef] 
9. Kuenzer, C.; Bluemel, A.; Gebhardt, S.; Quoc, T.V.; Dech, S. Remote sensing of mangrove ecosystems: A review. Remote Sens. 2011, 3, 878-928. [CrossRef]

10. Rauste, Y.; Hame, T.; Pullianen, J.; Heiska, K.; Hallikainen, M. Radar-based forest biomass estimation. Int. J. Remote Sens. 1994, 15, 2797-2808. [CrossRef]

11. Lucas, R.M.; Mitchell, A.L.; Rosenqvist, Å.; Proisy, C.; Melius, A.; Ticehurst, C. The potential of L-band SAR for quantifying mangrove characteristics and change: Case studies from the tropics. Aquat. Conserv. Mar. Freshw. Ecosyst. 2007, 17, 245-264. [CrossRef]

12. Mermoz, S.; Réjou-Méchain, M.; Villard, L.; Le Toan, T.; Rossi, V.; Gourlet-Fleury, S. Decrease of L-band backscatter with biomass of dense forests. Remote Sens. Environ. 2015, 159, 307-317. [CrossRef]

13. Cornforth, W.A.; Fatoyinbo, T.E.; Freemantle, T.P.; Pettorelli, N. Advanced Land Observing Satellite Phased Array type L-band SAR (ALOS PALSAR) to inform the conservation of mangroves: Sundarbans as a case study. Remote Sens. 2013, 5, 224-237. [CrossRef]

14. Wang, Y.; Imhoff, M.L. Simulated and observed L-HH radar backscatter from tropical mangrove forests. Int. J. Remote Sens. 1993, 14, 2819-2828. [CrossRef]

15. Proisy, C.; Mougin, E.; Fromard, F.; Trichon, V.; Karam, M.A. Interpretation of polarimetric radar signatures of mangrove forests. Remote Sens. Environ. 2000, 71, 56-66. [CrossRef]

16. Clewley, D.; Lucas, R.; Accad, A.; Armston, J.; Bowen, M.; Dwyer, J.; Pollock, S.; Bunting, P.; Eyre, T.; Kelly, A.; et al. An approach to mapping forest growth stages in Queensland, Australia through integration of ALOS PALSAR and Landsat sensor data. Remote Sens. 2012, 4, 2236-2255. [CrossRef]

17. Neumann, M.; Saatchi, S.; Ulander, L.M.H.; Fransson, J.E.S. Assessing performance of L- and P-band polarimetric interferometric SAR data in estimating boreal forest above-ground biomass. IEEE Trans. Geosci. Remote Sens. 2012, 50, 714-726. [CrossRef]

18. Freeman, A. Fitting a two-component scattering model to polarimetric SAR data from forests. IEEE Trans. Geosci. Remote Sens. 2007, 45, 2583-2592. [CrossRef]

19. Freeman, A.; Durden, S.L. A three-component scattering model for polarimetric SAR data. IEEE Trans. Geosci. Remote Sens. 1998, 36, 963-973. [CrossRef]

20. Maity, S.; Patnaik, C.; Parihar, J.S.; Panigrahy, S.; Reddy, K.A. Study of physical phenomena of vegetation using polarimetric scattering indices and entropy. IEEE J. Sel. Top. Earth Obs. Remote Sens. 2011, 4, 432-438. [CrossRef]

21. Cloude, S.R.; Pottier, E. An entropy based classification scheme for land applications of polarimetric SAR. IEEE Trans. Geosci. Remote Sens. 1997, 35, 68-78. [CrossRef]

22. Singh, G.; Yamaguchi, Y.; Park, S.-E. General four-component scattering power decomposition with unitary transformation of coherency matrix. IEEE Trans. Geosci. Remote Sens. 2013, 51, 3014-3022. [CrossRef]

23. Arii, M.; van Zyl, J.J.; Kim, Y. A general characterisation for polarimetric scattering from vegetation canopies. IEEE Trans. Geosci. Remote Sens. 2010, 48, 3349-3357. [CrossRef]

24. Lee, J.-S.; Pottier, E. Polarimetric Radar Imaging from Basics to Applications; CRC Press: Rochester, New York, USA, 2009.

25. Semesi, A.K. Developing management plans for the mangrove forest reserves of mainland Tanzania. Hydrobiologia 1992, 1-3, 1-10.

26. Ochieng, C. Research Master Plan for the Rufiji Floodplain and Delta 2003-2013; Environmental Management and Biodiversity Conservation of Forests Woodlands and Wetlands of the Rufiji Delta and Floodplain; Rufiji Environmental Management Project: Dar es Salaam, Tanzania, 2002.

27. Beentje, H.; Bandeira, S. Field Guide to the Mangrove Trees of Africa and Madagascar; Kew Publishing: London, UK, 2007.

28. Xtide: Harmonic Tide Clock and Tide Predictor. Available online: http://www.flaterco.com/xtide/ xtide.html\#contents (accessed on 10 August 2015).

29. Center for Sustainability and the Global Environment. Available online: http://nelson.wisc.edu/sage/dataand-models/riverdata/station_table.php?qual=256\&filenum=2130 (accessed on 10 August 2015).

30. Lavalle, M.; Wright, T. Absolute Radiometric and Polarimatric Calibration of ALOS PALSAR Products Generated Within ADEN; European Space Agency: Frascati, Italy, 2009.

31. Ainsworth, T.L.; Lee, J.S. A new method for a posteriori polarimetric SAR calibration. In Proceedings of the IEEE International Geoscience and Remote Sensing Symposium, Sydney, Australia, 9-13 July 2001; pp. 420-422. 
32. Lee, J.-S.; Grunes, M.R.; de Grandi, G. Polarimetric SAR speckle filtering and its implication for classification. IEEE Trans. Geosci. Remote Sens. 1999, 37, 2363-2373.

33. Small, D.; Holecz, F.; Meier, E.; Nuesch, D. Absolute radiometric correction in rugged terrain: A pleas for integrated radar brightness. In Proceedings of IEEE International Geoscience and Remote Sensing Symposium (IGARSS), Seattle, WA, USA, 6-10 July 1998; pp. 330-332.

34. Cloude, S.R. Uniquenes of target decomposition theorems in radar polarimetry. In Direct and Inverse Methods in Radar Polarimetry; Boerner, W.-M., Cram, L.A., Holm, W.A., Stein, D.E., Wiesbeck, W., Keydel, W., Giuli, D., Gjessing, D.T., Molinet, F.A., Brand, H., Eds.; Springer: Berlin, Germany, 1992; pp. 267-296.

35. Cloude, S.R. Polarisation Applications in Remote Sensing; Oxford University Press: Oxford, UK, 2009.

36. Dickinson, C.; Siqueira, P.; Clewley, D.; Lucas, R. Classification of forest composition using polarimetric decomposition in multiple landscapes. Remote Sens. Environ. 2013, 131, 206-214.

37. Praks, J.; Colin Koeniguer, E.; Hallikainen, M.T. Alternatives to target entropy and alpha angle in SAR polarimetry. IEEE Trans. Geosci. Remote Sens. 2009, 47, 2262-2274. [CrossRef]

38. Van Zyl, J.J.; Kim, Y.; Arii, M. Requirements for model based decompositions. In Proceedings of the IEEE International Geoscience and Remote Sensing Symposium (IGARSS), Piscataway, NJ, USA, 7-11 July 2008; pp. V417-V420.

39. Antropov, O.; Rauste, Y.; Hame, T. Volume scattering modelling in PolSAR decompositions: Study of ALOS PALSAR data over boreal forest. IEEE Trans. Geosci. Remote Sens. 2011, 49, 3838-3848. [CrossRef]

40. Liesenberg, V.; Gloaguen, R. Evaluating SAR polarization modes at L/band for forest classification purposes in Eastern Amazon, Brazil. Int. J. Appl. Earth Obs. Geoinf. 2013, 21, 122-135. [CrossRef]

41. Kobayashi, S.; Omura, Y.; Sanga-Ngoie, K.; Widyorini, R.; Kawai, S.; Supriadi, B.; Yamaguchi, Y. Characteristics of decomposition powers of L-band multi-polarimetric SAR in assessing tree growth of industrial plantation forests in the tropics. Remote Sens. 2012, 4, 3058-3077. [CrossRef]

42. Praks, J.; Antropov, O.; Hallikainen, M. LIDAR-Aided SAR interferometry studies in boreal forest: Scattering phase center and extinction coefficient at X- and L-band. IEEE Trans. Geosci. Remote Sens. 2012, 50, 3831-3843. [CrossRef]

(C) 2016 by the authors; licensee MDPI, Basel, Switzerland. This article is an open access article distributed under the terms and conditions of the Creative Commons by Attribution (CC-BY) license (http://creativecommons.org/licenses/by/4.0/). 